\title{
Stakeholder Analysis of Environmental Policymaking Process in Thailand
}

\author{
Kittisak Prukkanone (Corresponding author) \\ College of Public Administration, Huazhong University of Science and Technology, China \\ E-mail: p.kittisak@outlook.com
}

\begin{abstract}
Guohua Wang
College of Public Administration, Huazhong University of Science and Technology, China

The Public Opinion Researching Center,

Huazhong University of Science and Technology, China
\end{abstract}

Received: March 23, 2016 Accepted: May 07, 2016 Published: June 01, 2016

doi:10.5296/jpag.v6i2.9364 URL: http://dx.doi.org/10.5296/jpag.v6i2.9364

\begin{abstract}
This article studied on the stakeholder analysis of environmental policymaking process in Thailand for classifying and analyzing the power and interests of stakeholders. The results illustrated the importance and influence among them and leaded to the better understanding about the environmental policymaking process of Thailand. This findings advantaged in the public administration aspect concerning the natural resources and environmental management by fulfill the gap to avoid undesirable affected that may harm the further the environmental policymaking process. The results found that the most important stakeholders are those who make final policy decisions in Thailand's Environmental Policymaking Process. They are three decision-makers; the Cabinet, the Minister of Natural Resources and Environment and the National Environment Board. They all have a legal and presumed claim and ability to influence policy decision making. The second group is the citizens, the communities, and the international organizations eager to democratize the natural resources and environmental management because they believe that liberalization from state hands could lead to better public accessibility and better the self-immunity, which, in turn, would enhance the efficiency and fairness in the utilization of natural resources and the country's democracy. Nevertheless, the results significantly indicated that the first group influenced the environmental policymaking process of Thailand in their direction more than the second group due to their power and interests.
\end{abstract}

Keywords: Stakeholder Analysis, Environmental Policy, Power and Interests, Policymaking Process 


\section{Introduction}

The word 'stakeholder' has assumed a prominent place in public and nonprofit management theory and practice in the last 20 years, and especially in the last decade. The term refers to persons, groups or organizations that must somehow be taken into account by leaders, managers and front-line staff (Bryson, 2004).

In policy decision or action, stakeholders are any individuals or groups who affect or are affected by the policy, strategy, outcome, or organizations' performance' (Mitchell et al. 1997). Stakeholder analysis is one of many methods that employed to describe the involvement of stakeholders within the policy process. Because public policy is most often a compromise or the result of negotiation among conflicting interests, stakeholder analysis is an analysis of the power structure of stakeholders involved in a policy decision-making process (Majchrzak, 1984).

Stakeholder Analysis refers to a range of techniques for mapping and understanding the power, positions, and perspectives of the players (stakeholders) who have an interest in, and/or are likely to be affected by, a particular policy reform. Stakeholder analysis can be defined as a methodology for gaining an understanding of a system, and for assessing the impact of changes to that system, by means of identifying the key stakeholders and assessing their respective interests (Grimble, 1998). Mitchell et al. (1997) noted that the main attributes of stakeholders are power and legitimacy and stakeholders could be either powerful or powerless and could have either more or less interest in a policy. This analysis is widely used in organizational research and evaluation. It is also useful in analysis of public policy, as the success of public policy and public organizations depends on the satisfaction of key stakeholders according to their concerns of what is valuable (Bryson, 2004).

In Thailand's Environmental Policymaking Process, each stakeholder had his or her own interests and agendas and accepted that not all of those would be accomplished. They differed in desires or intentions in terms of policy goals and motives behind the policy, such as natural resources competition, public accessibility and participation, economic motives or market forces, diversity of utilization. Each issue is emphasized and interpreted differently among different stakeholders. Stakeholder analysis could be a meaningful method to discover who is involved in the policy process, what their interests are, and what their strategies are in influencing the policy. Specifically, it would address which interest groups were involved in Thailand's environmental policymaking process.

For this article, the Constitution of the Kingdom of Thailand B.E. 2550: A.D. 2007 (The 2007 Constitution) (The 2007 Constitution, 2007) was claimed as the scope of study. After the enactment of constitution, interest groups realized the impact of this law and the enormous opportunities for changes in the participation structure on environmental management. This included the policymaking process of the case study, Environmental Quality Management Plan 2012-2016 (EQM Plan 2012-2016) (EQM Plan, 2012) which the extensive involvement of stakeholders came from various provisions that intended to enhance the rights of people on environmental management under the participatory democracy concept. As Rowley \& Moldoveanu (2003) observed, the stakeholders mobilized to ensure that their interests (either 
economic or political) would be included and protected (Monwipa, 2008).

\section{Classification of the Stakeholders}

The first step in a stakeholder analysis is to clarify the research or policy change objective being discussed, and to outline the consequences that will flow from the policy reform. As Majchrzak (1984) suggested an analysis of stakeholders starting with identifying key stakeholders. Bryson (2004) describes this step as the way to identified stakeholders and their interests, clarifying stakeholders' views of a focal organization (or other entity), identifying some key strategic issues and beginning the process of identifying coalitions of support and opposition.

To identify key stakeholders for this research, the Policymaking Context of Environmental Quality Management Plan 2012-2016 was simulated by applied the concept of environmental policymaking in government (Roberts, 2004) to conceptualize the environmental policy formulation as a cycle, which focused on the five main components (policy environment, inputs, government, outputs, and outcomes).

For purpose of this article that emphasizes on the policy formulation process, the list of all stakeholders was based on the category of entities or actors influencing environmental policy and their involvement which provided on the four main components (except outcomes) those are; policy environment, inputs, government, and outputs as shown in Figure 1.

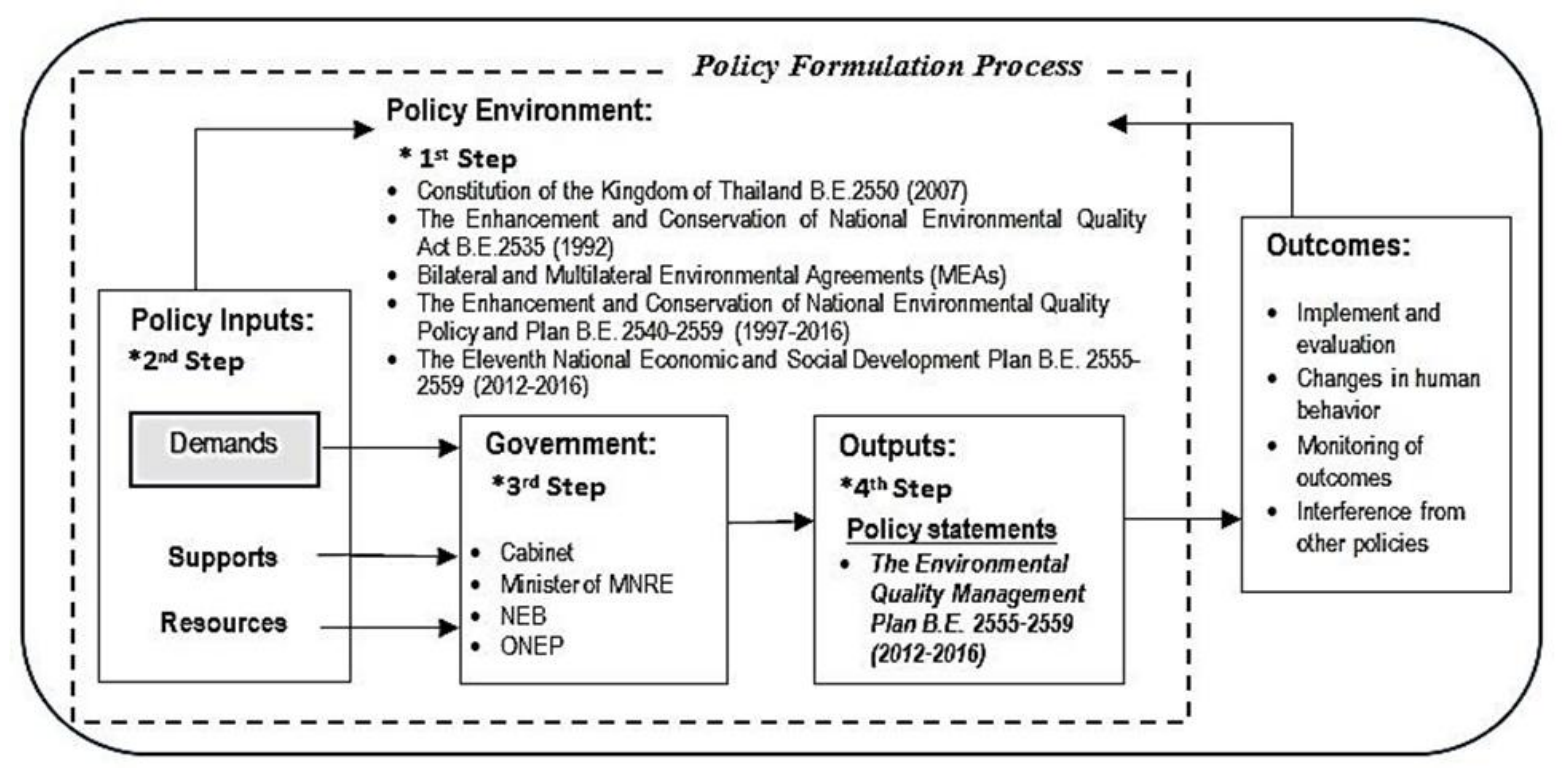

Note: * step of the policy formulation process adapted from Roberts (2004)

\section{Figure 1: Policymaking Context of Environmental Quality Management Plan 2012-2016}

\subsection{Policy Environment}

In this component, it was considered as the framework on participation of this research. The relevant actors were categorized their roles into two aspects those are shaped the policy environment which are consist; 


\section{$\triangle$ Macrothink}

1) The political complexion of the government aspect and prevailing public political ideologies in environmental issue: This sub-component contained three relevant actors, the first actor was the 2007 Constitution played a major role on behalf of the supreme law of Thailand which prevailed over other laws passed by parliament. In addition, the second actor, the NEQ Act 1992 was another actor which acted as the principle of environmental law in Thailand. Finally, the third actor, Multilateral Environmental Agreements (MEAs) had important role in this context which bonded the international agreements created between two or multiple nations that pledged to conduct their operations in such a way that limited negative environmental impacts (UNEP, 2016).

To identify the key stakeholders in this sub-component, the several provision of the 2007 Constitution and the Enhancement and Conservation of National Environmental Quality Act B.E.2535: A.D. 1992 (NEQ Act 1992) (NEQ Act, 1992) were considered according to the opportunities for citizen to participate in environmental policy-formulation process (see Box 1).

Box 1: The Policy Environment under NEQ Act 1992

\footnotetext{
Section 13. The National Environment Board shall have the power and duty as follows

(1) To submit policy and plan for enhancement and conservation of national environmental quality to the cabinet for approval.

Section 21. In the performance of its duties under this Act, the National Environment Board may entrust the Office of Natural Resources and Environmental Policy and Planning, .....under the Ministry of Natural Resources with the operation or preparation of propositions to be made to the National Environment Board for further actions.

Section 35. The Minister shall, with the approval of the National Environment Board, formulate an action plan called "Environmental Quality Management Plan" for implementation of the national policy and plan for enhancement and conservation of environmental quality determined by virtue of section 13 (1).

The Environmental Quality Management Plan pursuant to the first paragraph shall be published in the Government Gazette. It shall be the duty of all government agencies concerned to take actions within their powers and functions that are necessary for effective implementation of the Environmental Quality Management Plan and in order to ensure that actions are taken to achieve the objectives and goals as prescribed, it shall be the duty of the Ministry of Natural Resources and Environment to give advice to government agencies and state enterprises which are concerned with the formulation of work plans or the taking of any actions with a view to implementing the Environmental Quality Management Plan.
}

Source: NEQ Act, 1992

Bound to the 2007 Constitution, this policy emphasized to strengthen the role of public in the natural resources and environmental management. There are three key stakeholders that support in this role which consist of: 1) Citizens; 2) Communities; and 3) Local Government Organizations (LGOs). For the NEQ Act 1992, Sections 13 (Para. 1), 21 and 35 were played as a major role; by authorized the process of policy formulation as well as the policy implementation to the seven key stakeholders those are: 1) National Environment Board (NEB); 2) Minister of Natural Resources and Environment (Minister of NRE); 3) Cabinet; 4) MONRE; 5) Government Agencies; 6) Office of Natural Resources and Environmental Policy and Planning ONEP; and 7) State Enterprise or State Own Enterprises (SOEs). 
In addition, for the participation aspect that related to MEAs, it was emphasized in the public hearing process. This policy opened opportunities to the two key stakeholders, 1) non-governmental organizations (NGOs) and 2) International Organizations, became as the participants in this process before ONEP operated the decision-making process by government.

2) The fundamental information about the economic and social circumstances, and the state of natural resources and environment: There are two main actors in this sub-component consisting of The NEQ Plan 1997-2017 and the Eleventh National Economic and Social Development Plan B.E. 2555-2559 $\left(11^{\text {th }}\right.$ NESD Plan 2012-2016). They presented and interpreted the fundamental information about the economic and social circumstances (NESDB, 2011), and the state of natural resources and environment of Thailand into public sphere through the policy framework which ONEP (the responsible agency) had to mediate these information into the environmental policy-formulation process. The key stakeholders that related to those two actors were 1) National Economic and Social Development Board (NESDB) and 2) National Environment Board (NEB) which involved to the policy in terms of the decision makers and regulator, according to the relevant laws for regulating about the economic and social circumstances, and the state of natural resources and environment.

\subsection{Policy Input}

Underneath this component, this research applied the concept of modern democracies policy of Easton (1965) that is 'modern democracies policy is made in response to the pressures, opportunities and constraints provided by a combination of three classes of input those are Demands, Supports, and Resources'. Those three sub-components were operated in the policy system. They configured the policy inputs on the different basis which could be described in each as follows;

1) Demands: 'The perceived problems affecting various interests will lead to pressure for policies to be formulated to address the problem' was a common role for the actors in this sub-component. There were five actors playing this role which consist of: 1) Thailand public opinion in environmental management; 2) Evaluated result of Thailand's Environmental Quality Management Plan 2007-2011; 3) The five year forecast on Political Economic Socio-cultural Technological Components ; 4) The five year forecast on the environmental management scenario; 5) The five year forecast on the environmental legislation and amendment.

Those actors were identified to be the seven key stakeholders which involved by their participation in term of the policy proposer, including: 1) Citizen; 2) Community; 3) The Thai Chamber of Commerce (TCC); 4) The Federation of Thai Industry (FTI); 5) NGOs; 6) Government Agencies; and 7) Academics/Scholars.

2) Supports: 'Public advocated and obeyed with the policy context' was the essential factor for conducting this process. Supports are given to the political system and not necessarily to the personalities and parties in power. In this research, there were four main actors including; 1) Citizen, 2) Community, 3) Government Agency, and 4) Media, they played a major role through the comprehensive public hearings which co-operated between them and the operator agency as ONEP. 


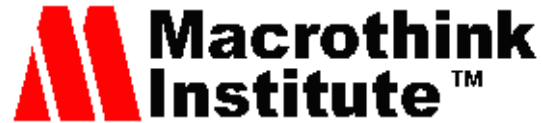

Journal of Public Administration and Governance

ISSN 2161-7104

Those actors were transformed to be the four key stakeholders which involved by their participation in term of the policy supporter, including: 1) Citizens; 2) Communities; 3) Government Agencies; and 4) Media.

3) Resources: The resources of this sub-component emphasized on 'The important things that required implementing the policy'. Ordinarily, the most important resource for any policy is often the money required to implement it, and the availability of this will constrain policy formulation. However, as focusing on the policy formulation, other resources were considered their signification and integrated in this sub-component those are the scientific information, technical, and the availability of natural resources and environmental services. Another resource that due to the contribution for this research, the administration of justice in this policy, considered as an important thing concerning the conflict resolution in natural resources and environmental management.

Those resources were transformed to be the seven key stakeholders which involved by their participation in term of the policy proposer, including: 1) Donors; 2) The Bureau of Budget (BOB); 3) International Organizations; 4) Academics/Scholars; 5) NGOs; 6) Ministry of Justice (MOJ) and 7) MONRE.

\subsection{Government}

The decision-making process within government was played by the four key stakeholders who are consisting of 1) ONEP, 2) National Environment Board (NEB), 3) Minister of Natural Resources and Environment (Minister of NRE), and 4) Cabinet. Their decision-making process depends on the authorization power that given to government from Section 13 (Para. 1), 25, and 35 of the NEQ Act 1992 (see Figure 2).

\subsection{Outputs}

The major role of this component was 'The implementations or actions that could change or affect the people's behavior to follow the policy context'. The major variables which contributed to the successful implementation of policy were taken into account, including other variables those were influenced or impacted by the implementation both in the positive and negative ways. The results found that there were fourteen actors those directly related to the successful in this policy, including 1) Citizens, 2) Communities, 3) Commercial and Services Sector, 4) Industrial Sector, 5) Tourism Sector, 6) Transportation Sector, 7) Agricultural Sector, 8) Government Agencies, 9) State Enterprise or State Own Enterprises (SOEs), 10) LGO; 11)Ministry of Justice(MOJ);12) Members of Parliament;13) Media; and 14)Academics/Scholars.

All relevant actors were related to this component in term of key stakeholders which involved with the policy regarding their contributions to the successful of policy implementation. Particularly, the Governmental Agencies, State Enterprises, as well as the LGOs, they are the legal-binding agencies under Sec. 35 of the NEQ Act 1992to take actions within their powers and functions those were necessary for effective implementation of the EQM Plan 2012-2016. 


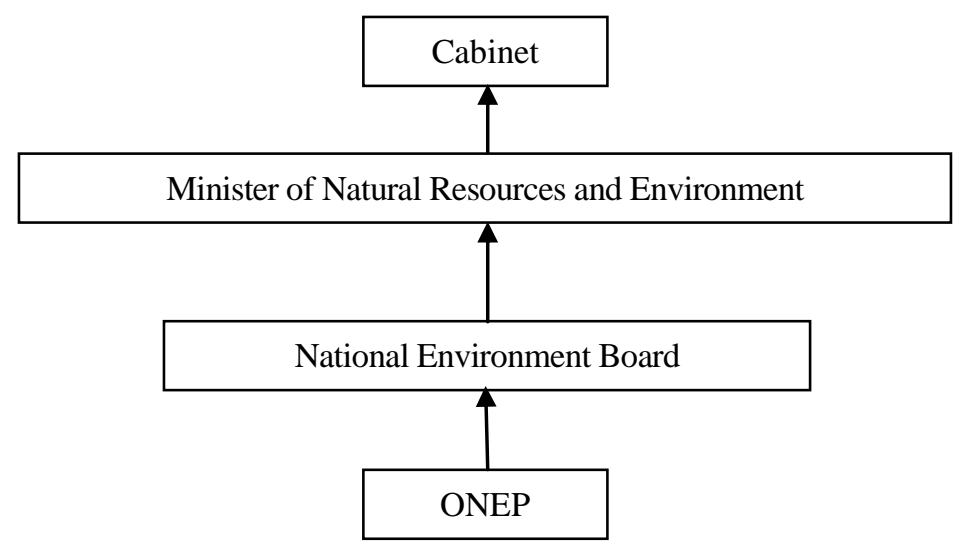

Figure 2: The Decision-Making Process within Government

\subsection{List of the Policy Formulation Process Stakeholders}

According to the above analytical results, the list of stakeholders is based on the categories of internal entities or actor influencing this policy which was categorized into 3 groups: 1) Political Group; 2) Private or Business Group; and 3) Public or Civic Group as illustrated in Table 1.

Table 1: List of the Policy Formulation Process Stakeholders

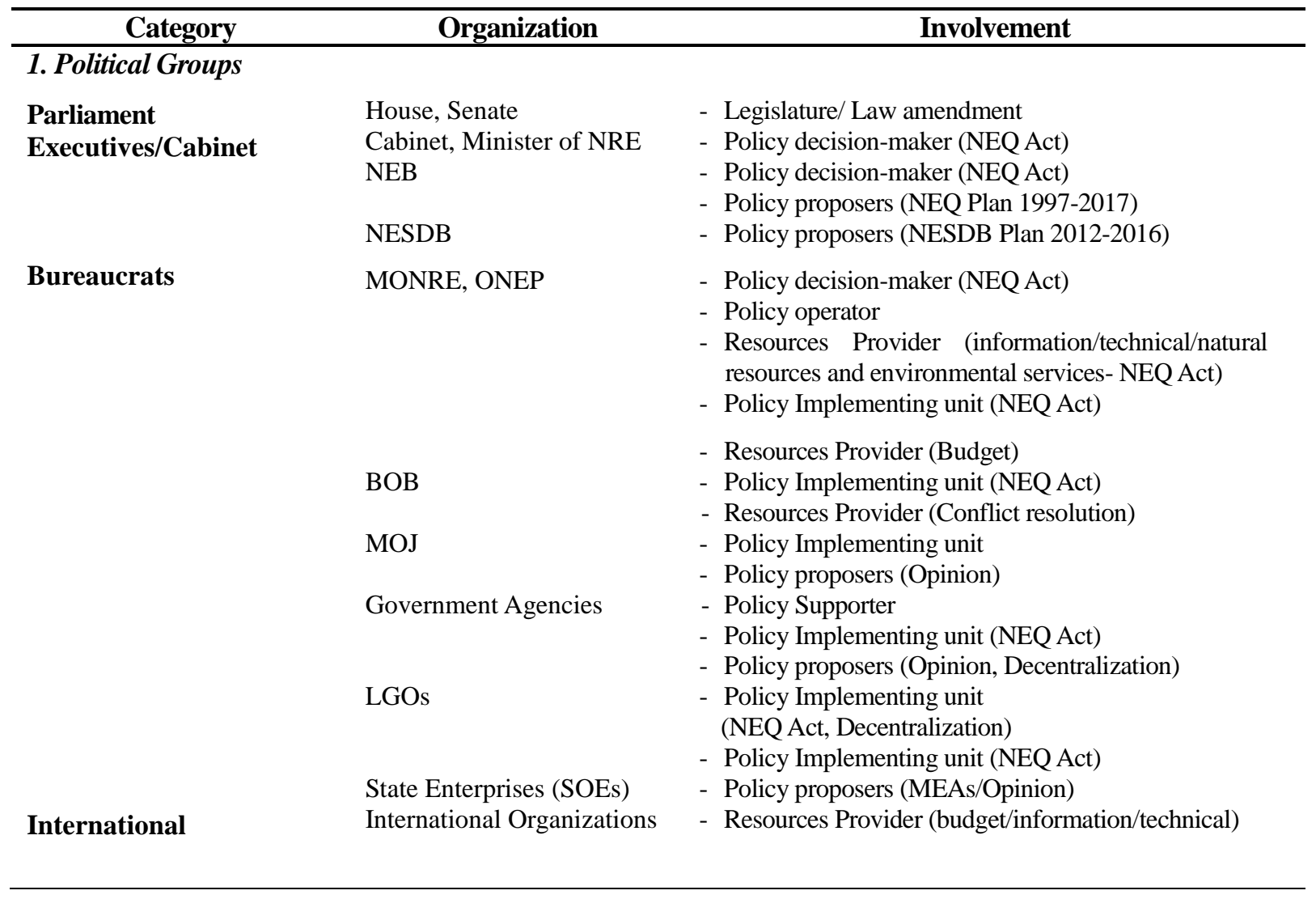




\begin{tabular}{|c|c|c|}
\hline Category & Organization & Involvement \\
\hline $\begin{array}{l}\text { 2. Private or } \\
\text { Business Groups }\end{array}$ & $\begin{array}{l}\text { FTI, TCC } \\
\text { Agricultural Sector } \\
\text { Industrial Sector, } \\
\text { Tourism Sector, } \\
\text { Transportation Sector, } \\
\text { Commercial/Services Sector }\end{array}$ & $\begin{array}{l}\text { - Interest Group } \\
\text { - Policy proposers (Opinion) } \\
\text { - Policy Implementing unit (NEQ Act) } \\
\text { - Farmer/ Agriculturist } \\
\text { - Policy Implementing unit (NEQ Act) } \\
\text { - Business entrepreneur } \\
\text { - Policy Implementing unit (NEQ Act) }\end{array}$ \\
\hline & $\begin{array}{l}\text { Media } \\
\text { Donors }\end{array}$ & $\begin{array}{l}\text { - Policy Supporter } \\
\text { - Policy Implementing unit } \\
\text { - Resources Provider (Budget) }\end{array}$ \\
\hline $\begin{array}{l}\text { 3. Public or } \\
\text { Civic Groups }\end{array}$ & $\begin{array}{l}\text { NGOs } \\
\text { Academics/Scholars } \\
\text { Citizens, Communities }\end{array}$ & $\begin{array}{l}\text { - Policy proposers } \\
\text { (MEAs/Opinion/Research-NEQ Act) } \\
\text { - Policy Implementing unit (NEQ Act) } \\
\text { - Resources Provider (budget/information/technical) } \\
\text { - Policy proposers (Opinion/Research) (NEQ Act) } \\
\text { - Resources Provider (information/technical) } \\
\text { - Policy Implementing unit } \\
\text { - Policy proposers (Opinion-Constitution) } \\
\text { - Policy Supporter } \\
\text { - Policy Implementing unit (NEQ Act) }\end{array}$ \\
\hline
\end{tabular}

\section{Power and Interests of Stakeholders}

To contribute this research, the power relation among government and society was focused by considering their interrelation in establishing and implementing the policy. This relation was analyzed in this step, to classify the various stakeholders in terms of their power in relation to the policy, and in terms of their interest in relation to the policy. 'Power' measures the influence they have over the policy, and to what degree they can help achieve, or block, the desired change. 'Interest' measures to what degree they are likely to be affected by the policy change, and what degree of interest or concern they have in or about it (Start and Hovland, 2004).

The power of the stakeholders is explained by decision making, resources at hand, their ability to mobilize resources, and their accessibility to policy decision makers. Power is defined by Max Weber (1947) as "the probability that one actor within a social relationship would be in a position to carry out his own will despite resistance" (as cited in Mitchell et al., 1997, p.865). In other words, it is the ability of the stakeholders to possess enough resources to make the outcomes they desire happen.

In addition to power, each stakeholder differs in interest in, desires, and attention to a particular policy. Rowley and Moldoveanu (2003) explained that stakeholders' degree of discontent or feeling of urgency is the primary condition driving them to influence the organizations. Stake holders will mobilize to protect or enhance their interests. Interest is viewed as their assumed "preferences based on [typically] economic utility maximization guiding their behavior" (p. 206). Interest can take many forms such as legal or moral rights, legal title, or ownership. Having a stake or interest, the stakeholders are affected (either benefited or harmed) by the organizations' policy and actions because they bear some risk in 
relation to the organization. Oftentimes rational or economic interests might guide stakeholders to make cost-benefit decisions to protect their interests. Still, many collective actions of social movements are not based on economic benefits alone. In some cases, interests might be based on shared belief or dogma, affiliation, or common identity. These shared perceptions and feelings of solidarity among members of the stakeholders could also guide them to protect their interests (Rowley and Moldoveanu, 2003).

Generally, stakeholders with high power, and interests aligned with the policy, are the people or organizations it is important to engage with fully and to bring on board. If trying to create policy change, these people are the targets of any campaign. At the very top of the 'power' list will be the 'decision makers', usually members of the government. Beneath these are people whose opinion matters - the 'opinion leaders'. Besides, stakeholders with high interest but low power need to be kept informed; if organized, they may form the basis of an interest group or coalition that can lobby for change. Those with high power but low interest should be kept satisfied and ideally brought around as patrons or supporters for the proposed policy change.

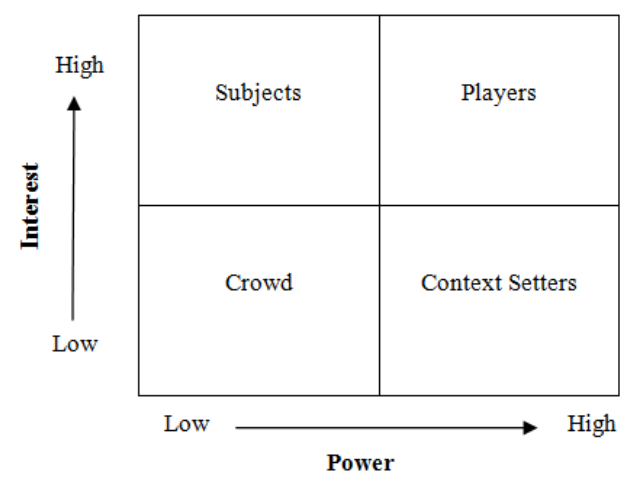

Figure 3: Power versus interest grid (Eden and Ackermann, 1998)

Power versus interest grids are described in detail by Eden and Ackernlann (1998) (see Figure 3 ), it typically help determine which players' interests and power bases must be taken into account in order to address the problem or issue at hand (Bryson, 2004). Four categories of stakeholders results based on their interest and power: (1) players, who have both high power and significant interest in the policy; (2) subjects, who have an interest but little power in the policy; (3) crowd, who have both low power and low interest in the policy, and(4) context setters; who have power but little direct interest in policy (Rowley and Moldoveanu, 2003). They also help highlight coalitions to be encouraged or discouraged, what behavior should be fostered and whose 'buy in' should be sought or who should be 'co-opted'. Finally, they provide some information on how to convince stakeholders to change their views. Interestingly, the knowledge gained from the use of such a grid can be used to help advance the interests of the relatively.

As mentioned above, to define the power versus interest grids in this policy, the study analyzed the list of the stakeholders (in Table 1) by determined the power and interest of stakeholders according to their responsibilities and involvement in terms of 'High or Low'. The analytical results that illustrated their status on the power versus interest grids, the 
stakeholders on policy formulation process of EQM Plan 2012-2016 in terms of their power and interests are arranged as followed (see Figure 4):

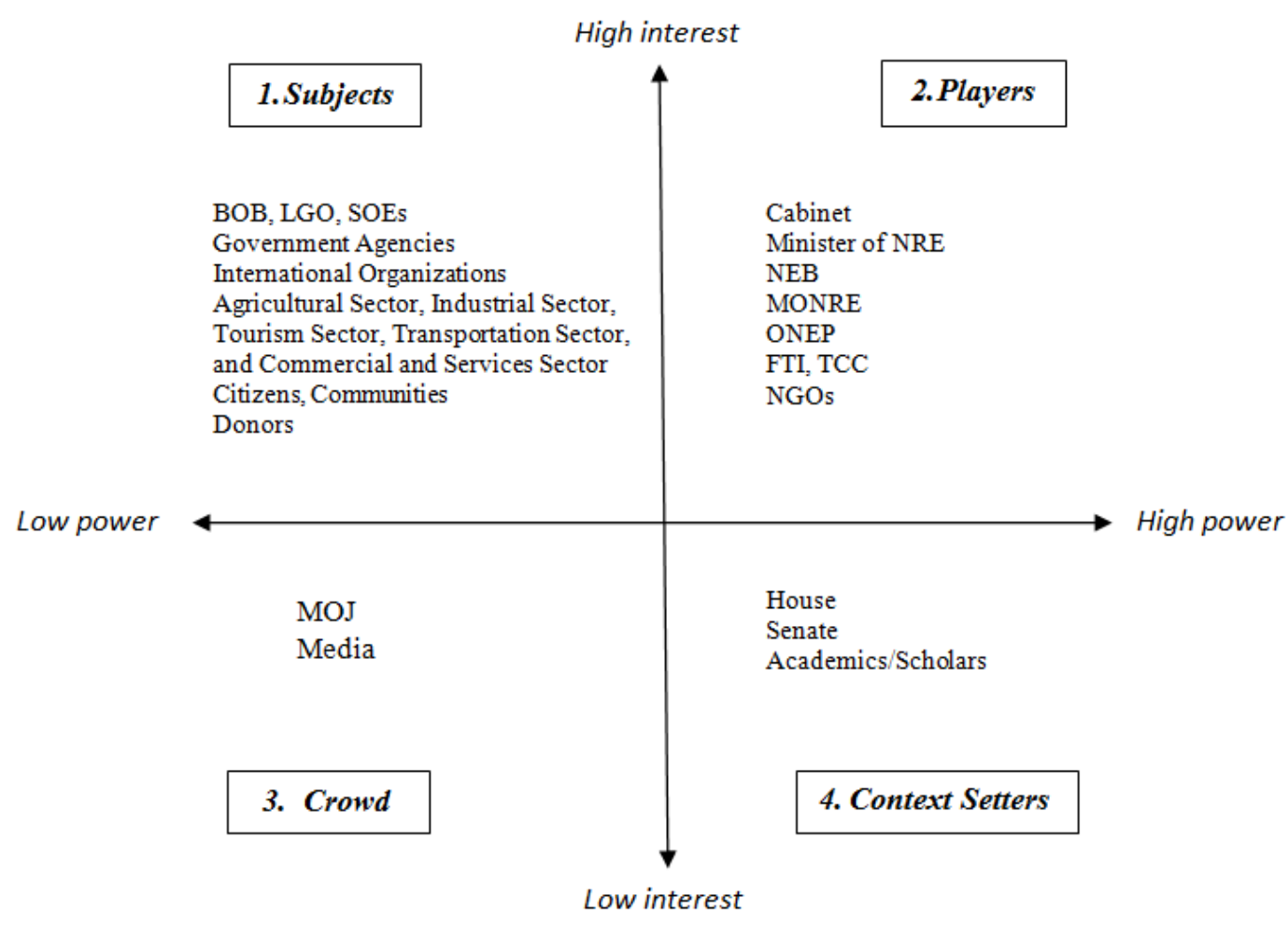

Figure 4: Power and Interests of the Stakeholders in Policy Formulation Process

\subsection{Subjects}

This is the biggest group of key stakeholders which covered half of key stakeholders of this policy (thirteen from 26 key stakeholders). All three categories of key stakeholders; 1) the political groups, 2) the private or business groups, and 3) the public group, have a high interest in the policy formulation process because it would impact their mandates, jobs and their concerns regarding living, quality of life, freedom of expression, public sphere, and public accessibility.

1) Political groups: The first category comprised of the Bureau of Budget (BOB), the Local Government Organization (LGO), the Government Agency, the State Enterprise or State Owned Enterprises (SOEs), and the International Organizations. They are directly related to their mandates (under the NEQ Act 1992) which are interested in implementing the policy. In other words, it can be said that the impacts in their interests were indicated the success of policy implementation.

2) Private or Business groups: The second category comprised of Agricultural Sector, Industrial Sector, Tourism Sector, Transportation Sector, Commercial and Services Sectors, and Donor. Their interest is the economic incentives which affected after the policy was implemented and driven by the government via the law and regulations which generated from the policy. A private or business organization, in general, whose primary goal is making money (a profit), as opposed to a donor organization which focuses a goal such as helping the community and is concerned with money only as much as necessary to keep the organization operating. Therefore, for contribution to this article, the predictable positive impacts that 
promoted the profit and interest of private or business sector and donor would be skipped to mention in this research.

For the negative impact in their interests from the policy, it was appeared in term of the law enforcement. The inconsistency of government and private sector was linked to the facing between government mandate and entrepreneurship which affected the interests both in aspect of timing (short and long terms) and boundary (domestic and international). This fact was confirmed by the interviewees that recognized with this problem by divided the situation of problem into 2 main issues as follow;

(1) Ability in competition - Private sector emphasized this issue for communicating about their concerned with the government, especially, in the market competition between Thai business and international business which based on the difference sources of law. The law enforcement in the origin of product and business entrepreneur were differenced and leaded to restrict their business interests by: 1) limit the number or types of businesses, 2) limit the ability of businesses to compete, and 3) reduce the incentive for businesses to compete. In this issue, the tradeoff between the impacts on natural resources and environment and their management must be carefully considered under the public consultation.

(2) Burden in business - Private sector accepted this problem on behalf of the affected person due to their business which related to the various laws and regulations in the same time. In their business, there are many law and regulations that may conflict or duplicate which were transformed to the heavy burden in the business. Private sector need to communicate with the government in this issue to avoid the other negative impacts that may significant affected to their business interest such as Business Governance System, Corporate Social Responsibility (CSR), Investor Relations (IR), and so on.

3) Public group: The third category has two representatives those are Citizens and Communities. They are interested in reshaping the natural resources and environmental management structure and institutions by releasing the authority from state hands. Their interest is covered both economic and non-economic incentives those concerned with the job, quality of life, including democratic values about their rights for living, freedom of expression, public sphere, and public accessibility.

Although the subjects are interested in shaping and implementing the policy, their power is less than the players and the context setters. It is difficult to access and drive resources to influence policy properly.

\subsection{Players}

The key stakeholders in this group are with high power and high interest in the policy. In Thailand's Environmental Policymaking Process, these status quo actors still have high power and a high interest in the natural resources and environmental management arena, even after the enactment of the 2007 Constitution opened ways for the participation of other stakeholders. Majchrzak (1984) elaborated that the players' power comes from their influence in decision making and their connections to and relationships with the status quo. Some of them are even those in power; thus, their resources are readily available, they have no doubt in their ability to mobilize resources, and they have accessibility to decision makers. In this policy, the player stakeholders were distributed in all categories but different in proportion.

1) Political groups: This group including the Cabinet, the Minister of NRE, the NEB, the MONRE, the ONEP, have resources at hand and the natural resources and environmental management are still under their control. All of them have separated authority covering every 
step of the policymaking process through their authorized (under the NEQ Act 1992) both in terms of: the policy proposers; the policy operator; the policy decision-maker; the policy implementing unit; and the resourced provider. Namely, the absolute power was authorized them to manage the related interests in the society.

2) Private or Business group and Public Group: Private sectors such as The Federation of Thai Industry (FTI), The Thai Chamber of Commerce (TCC) and NGOs were representatives from their category. The relation between them was very close in term of decision-maker in the policymaking process under the NEQ Act 1992 which emphasized in promoting the public participation sphere which participated in the concept common but differentiated proportion. This means Private sectors and NGOs have rights to participate in common terms of the authority but the proportion or intensive concerning their action still controlled by government.

For the interests of key stakeholders in this group, FTI and TCC, the interest groups of private sector are also considered to be in this group due to their close connection with the state and their interests are more often driven by economic incentives under the collaborative between the political group and private or business group. The mutual assistance between those two groups was the cause of problem in natural resources and environmental conflicts (Thawilwadee, 2000), particularly, in the way of the development project or the megaproject such as Dam, Highway, and other infrastructure. For instance, in 1980, the government project to build the Nam Choan Dam in the wildlife sanctuary, at Kanchanaburi province. Many people opposed the project, and this event became a significant force in environmental movement in Thailand.

\subsection{Crowd}

This group has both less power and less interest in the policy. There are only two key stakeholders due to their actions in this policy and impacts from this policy which the Ministry of Justice (MOJ) and the Media were placed in this group. Namely, the affected by the environmental policy is typically regarded as being far from their job, compared to other public policies such as social welfare, taxes, finance, and trade. Therefore, it is not surprising that MOJ and Media have little concern about participation in environmental policymaking process.

MOJ was placed in this group because the mandate of MOJ is not related to the context of problem in this policymaking process which needed to emphasize the environmental justice and dispute resolution between public and government in the natural resources and environmental issue. Although the mission of MOJ was mandated to ensure public access to justice and develop administrative judicial management but it only conducted in preliminary process and needed the main mechanism about the dispute resolution such as the Administrative Courts for taking this role.

For the media, it was placed there because the general Thai public does not aware about what is going to change in natural resources and environmental management, as long as they are able to consume and utilize them. That directly reflected to the media which is necessary to propose the topic that public was more concerned such as entertainment news, economic news, political news etc., meanwhile, the important of natural resources and environmental news was placed in last priority. 


\subsection{Context setters}

The key stakeholders in this group are the high power groups involved in the policy-decision making but have less interest. The members of parliament, house and senate, are categorized in this group because they have power through the National Assembly or the Parliament of Thailand as the legislative branch of the government of Thailand.

In addition to the legislative function, the law amendment function also played as an important role in decision making of the members of parliament. Particularly, in this policy, it has requirement on legislative and law amendment in the relevant laws that contribute the natural resources and environmental management.

Besides the members of parliament, Academics/Scholars has important role according to the NEQ Acts 1992 (Section 18) which id regulated that 'The National Environment Board may appoint an expert committee or sub-committee to consider or carry out any matter as may be entrusted by the National Environment Board'. This aspect was more emphasized by the concept of environmental policymaking which shows the information needs of policy makers are both social science and natural science (Dovers et al., 2001). Notwithstanding, the members of parliament and academics/scholars have the high power to influence in the policymaking process but they are not affected in any aspect by the policy due to the indirect mandate of them.

\section{Conclusion}

This study classified and analyzed power and interests of stakeholders to illustrate the importance and influence among them which can be contributed the understanding about the environmental policymaking process of Thailand. This findings advantaged in the public administration aspect concerning the natural resources and Environmental management by fulfill the gap to avoid undesirable affected that may harm the further the environmental policymaking process.

The importance of stakeholders is indicated by their responsibility for and influence on the particular policy. The importance of stakeholders is determined by a claim and their ability to influence. That is, they have a legal, moral or presumed claim on the organization and have ability to influence the direction, process or outcome of its policy (Mitchell et al., 1997).

In Thailand's Environmental Policymaking Process the most important stakeholders are those who make final policy decisions. They are three decision-makers; the Cabinet, the Minister of Natural Resources and Environment and the National Environment Board. They all have a legal and presumed claim and ability to influence policy decision making. The Cabinet has to make final decisions in the policy approval by the submission from the Minister of Natural Resources and Environment. However, the National Environment Board also has authority to screen the policy and plans in preliminary of this approval process.

Although the three decision-makers have a great deal of influence on the policy approval, their power is not absolute. During the process of policymaking, other stakeholders in 'the players group of stakeholders' could have an impact on policy decisions those are bureaucrats, 
the interest group of private sector (FTI and TCC), and NGOs. Their influence supports rather than opposes restructuring the policymaking system on the natural resources and environmental management due to their mutual assistances and interests. However, their desires regarding the policymaking details are somewhat different which indicates following the public participation that valid in the policy concept including the Public-Private Partnership and the Good Governance. Whereas bureaucrats and the interest group of private sector support Public-Private Partnership and a business scheme, NGOs - are likely to support democratization and the good governance.

The second group is the citizens, the communities, and the international organizations eager to democratize the natural resources and environmental management because they believe that liberalization from state hands could lead to better public accessibility and better the self-immunity, which, in turn, would enhance the efficiency and fairness in the utilization of natural resources and the country's democracy.

Nevertheless, the results significantly indicated that the first group influenced the environmental policymaking process of Thailand in their direction more than the second group due to their power and interests.

\section{Acknowledgement}

We are grateful for the achievement of this study to the relevant people offering to us for their resources and support information the research analysis.

\section{References}

Bryson, J. M. (2004). What to do when stakeholders matter. Public Management Review, 6(1), 21-53.

Bureekul, T. (2000). Public Participation in Environmental Management in Thailand. Bangkok: King Prajadhipok's Institute.

Eaton D. (1965). A System Analysis of Political Life, New York: Wiley.

Eden, C., \& Ackermann, F. (1998). Makina Strate 8J: The Journey of Strategic Management, London: Sage Publications.

Enhancement and Conservation of National Environmental Quality Act B.E. 2535 (in Thai). (1992). Royal Gazette, Thailand. Vol. 109.

Grimble, R. (1998). Stakeholder methodologies in natural resource management. Socioeconomic Methodologies, Best Practice Guidelines. Chatham, UK: Natural Resources Institute.

Jane, R. (2004). Environmental Policy, London: Routledge (an imprint of the Taylor \& Francis Group).

Majchrzak, A. (1984). Methods for policy research. London: Sage Publications.

Mitchell, R., Agle, B., \& Wood, D. (1997). Toward a theory of stakeholder identification and 
salience: Defining the principle of who and what really counts. The Academy of Management Review, 22(4), 853-886.

Norton, T. W., Dovers, S. R., \& Handmer, J. W. (2001). Ignorance, uncertainty and ecology: key themes. In: Ecology, uncertainty and policy: Managing ecosystems for sustainability. Prentice Hall/Pearson Education Ltd, Harlow, England, pp. 1-25.

Office of Natural Resources and Environmental Policy and Planning (ONEP) Thailand. (2013). Environmental Quality Management Plan (in Thai). [Online] Available:

http://www.onep.go.th/index.php?option=com_content\&view=article\&id=2761\&Itemid=173. (October 30, 2013)

Rowley, T., \& Moldoveanu, M. (2003). When will stakeholder groups act? An interest- and identity based model of stakeholder group mobilization. Academy of Management Review, 28(2), 204-219.

Start, D., \& Hovland, I. (2004). Tools for policy impact: a handbook for researchers. London: Overseas Development Institute. (http://odi.org.uk/resources/download/156.pdf).

The Constitution of the Kingdom of Thailand B.E.2550 (in Thai), August 24, 2007, Royal Gazette, Thailand. Vol. 124.

United Nations Environment Programme (UNEP). (2016). MEA IMPLEMENTATION SUPPORT. [Online] Available:

http://www.unep.org/delc/MEAImplementationSupport/tabid/54401/Default.aspx (March 28, 2016)

Wongrujira, M. (2008, December 5-7). Stakeholder Analysis of Communication Policy Reform in Thailand. In Dr. Stephen McDowell Chair, the CPRSouth3: Conference on "Transformation Strategies for Telecom Operators". Organized by Beijing University, China.

Wheare, K. C. (1963). Federal Government, $4^{\text {th }}$ edition. London: Oxford University Press.

\section{Copyright Disclaimer}

Copyright for this article is retained by the author(s), with first publication rights granted to the journal.

This is an open-access article distributed under the terms and conditions of the Creative Commons Attribution license (http://creativecommons.org/licenses/by/3.0/). 